\title{
Epigenetic Modulators Enhance Constitutive and Liver-Specific Reporter Expression in Murine Liver Progenitor Cell Lines
}

\author{
Luke Aris Diepeveen, $\mathrm{PhD},{ }^{1}$ Michel Elyse Watson, BSc, ${ }^{1,2}$ Sarah Beth McSpadden, Bsc, ${ }^{3}$ \\ Robyn Patricia Strauss, Bsc, ${ }^{3}$ Bernard Andrew Callus, $\mathrm{PhD},{ }^{3}$ and George Cheng Yeoh, $\mathrm{PhD}^{1-3}$
}

Stem cells expressing reporter constructs are extremely useful for their tracking in vivo or for determining cell lineage fate in vivo and in vitro. We generated liver progenitor cell (LPC) lines from actin-EGFP and TATGRE-lacZ mice. LPCs from the actin-EGFP mouse facilitate cell tracing following transplant as the reporter is constitutively expressed. LPCs from the TAT-GRE-lac $Z$ mouse express $\beta$-galactosidase under the control of the tyrosine aminotransferase (TAT) promoter and are only active in mature hepatocytes. We found that the utility of such LPC lines becomes severely limited by downregulation of transgene expression following extended culture. We show that epigenetic mechanisms are responsible for suppressing expression of both transgenes. Enhancement of transgene expression in both LPC lines was achieved by treating the cell lines with either the histone acetylating agent sodium butyrate or the DNA demethylating agent 5-azacytidine.

\section{Introduction}

$\mathbf{T}$ He Developmental Limitations of adult progenitor cells are similar to other embryonic cells and this is attributable to reversible epigenetic modifications. ${ }^{1}$ Embryonic stem cells and potentially other adult stem cells may retain their pluripotency by avoiding these epigenetic changes. Cells and cell lines carrying reporter constructs are useful as they can be tracked in vivo following transplant or their lineage fate can be established in vivo and in vitro when they harbor the appropriate reporter. However, studies have demonstrated that this reporter expression can decrease with continuous passaging due to these epigenetic changes. ${ }^{2}$ Treatment of cell lines with epigenetic modulators such as sodium butyrate $(\mathrm{NaB})$ or 5 -azacytidine $(5$-aza $\mathrm{C})$ improves the reprogramming of different cell types. ${ }^{3}$

$\mathrm{NaB}$ and 5-aza $\mathrm{Chave}$ been used to investigate the direct and indirect effects of induced epigenetic changes in chromatin acetylation and DNA methylation, respectively, in many cell types, including both normal and malignant cells. ${ }^{4-6} \mathrm{NaB}$ has been reported to inhibit proliferation, stimulate differentiation, and restore gene expression in cultured cells. ${ }^{7,8}$ Treatment of cells by $\mathrm{NaB}$ results in histone hyperacetylation by inhibiting histone deacetylases. ${ }^{9,10}$ This induces histone $\mathrm{H} 3$ acetylation and promotes DNA demethylation, which alters expression of pluripotency-associated genes. ${ }^{11}$ In contrast, 5-aza C stimulates the removal of methyl groups from DNA by inhibiting
DNA methyltransferases, ${ }^{12,13}$ which can induce gene expression, including genes that regulate differentiation. ${ }^{14,15}$

Liver progenitor cells (LPCs) are considered to be facultative hepatic stem cells that can differentiate into functional hepatocytes and cholangiocytes in the setting of chronic liver injury. ${ }^{16,17}$ LPCs have assumed increased significance given their therapeutic potential, that is, their stem-cell like ability to regenerate the liver. ${ }^{18,19}$ In contrast, the application of mature hepatocytes for therapeutic intervention is hampered by their inability to proliferate and maintain function when expanded by long-term in vitro culture. ${ }^{20}$

To study hepatocyte differentiation from LPCs, cell lines were generated from the TAT-GRE-lacZ mouse and designated BMEL-TAT. ${ }^{21}$ BMEL-TAT expresses $\beta$-galactosidase under the control of the liver-specific tyrosine aminotransferase (TAT) promoter, which is only expressed in mature hepatocytes. ${ }^{22}$ In this multicopy transgene model, the $\beta$-galactosidase reporter faithfully reflects the endogenous expression of liver-specific TAT. $^{23}$ Unexpectedly, the utility of this cell line was compromised when transgene expression was diminished after they were extensively expanded in long-term culture.

To ascertain whether epigenetic mechanisms were responsible, we assessed the effects of the $\mathrm{NaB}$ and 5-aza $\mathrm{C}$ on the activity of the $\beta$-galactosidase reporter gene in BMEL-TAT cells. We show that both agents were able to enhance reporter gene expression. However, in this model, we were unable to ascertain whether epigenetic modulation suppressed the ability

\footnotetext{
${ }^{1}$ The Centre for Medical Research, Harry Perkins Institute of Medical Research, Nedlands, WA, Australia.

${ }^{2}$ Center for Cell Therapy and Regenerative Medicine, School of Medicine and Pharmacology, Crawley, WA, Australia.

${ }^{3}$ School of Chemistry and Biochemistry, University of Western Australia, Crawley, WA, Australia.
} 
of the cells to differentiate or whether they have downregulated expression of the reporter. To test whether a reporter gene that is expressed independently of the differentiated status of the LPC is attenuated by epigenetic mechanisms, we generated multicopy transgenetic LPCs from the actin-EGFP mouse ${ }^{24}$ where constitutive EGFP expression is regulated by the actin promoter and designated as BMEL A-EGFP. We show that $\mathrm{NaB}$ and 5-aza $C$ enhance EGFP reporter expression in these LPCs. We also show that $\mathrm{NaB}$ and 5-aza $\mathrm{C}$ reactivate reporter expression in extensively passaged (p57) BMEL A-EGFP cells, in which the transgene was almost completely extinguished. We conclude that epigenetic mechanisms operate to downregulate reporter genes in progenitor/stem cells as they are passaged and this reduces their utility. Epigenetic modification can increase the activity of the transgenes and restore their utility.

\section{Materials and Methods}

\section{$\angle P C$ isolation}

Livers from 14-day gestation mice were washed with a warm $\left(37^{\circ} \mathrm{C}\right)$ balanced salt solution $(0.5 \mathrm{~mL}$ per liver; BSS $)$, and lobes were separated and freed from the adjoining gut and
FIG. 1. Low-passage BMEL-TAT LPCs (p9) and BMEL A-EGFP (p10) express epithelial and not mesenchymal cell markers. BMEL-TAT (A) and BMEL A-EGFP (B) LPCs stain positively for epithelial markers such as ECadherin $(\mathrm{a}-\mathrm{c})(\mathrm{j}-\mathrm{l})$ and EpCAM $(\mathrm{d}-\mathrm{f})$ $(\mathrm{m}-\mathrm{o})$, respectively. BMEL-TAT $(\mathrm{g}-\mathrm{i})$ and BMEL A-EGFP ( $\mathrm{p}-\mathrm{r}$ ) cells do not express the mesenchymal cell marker vimentin. Exposure times were 1/20 and $1 / 4 \mathrm{~s}$ for DAPI and AF488/594 images, respectively. Scale bars represent $100 \mu \mathrm{m}$. LPCs, liver progenitor cells; TAT, tyrosine aminotransferase. Color images available online at www.liebertpub.com/tec

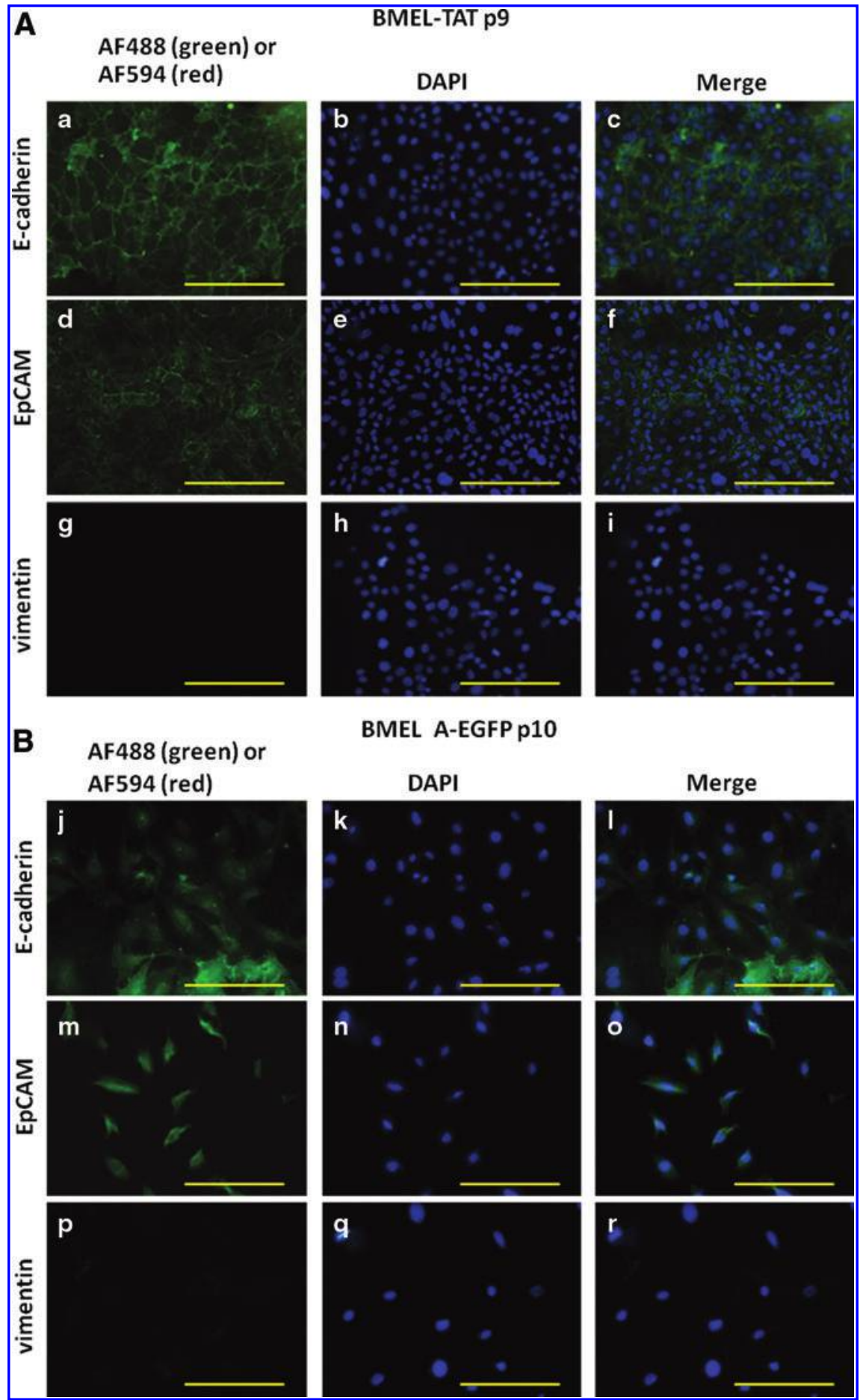


mesenchyme using fine forceps. Lobes from each liver were incubated in $0.5 \mathrm{~mL}$ of BSS containing $0.6 \mathrm{mg}$ of collagenase $\mathrm{H}$ (Boehringer Mannheim) for $20 \mathrm{~min}$ at $37^{\circ} \mathrm{C}$ with gentle mixing every $5 \mathrm{~min}$. Following centrifugation for $5 \mathrm{~min}$ at 300 $g$, the collagenase solution was replaced with a growth medium that comprised Williams' E medium (Sigma-Aldrich) supplemented with $2.5 \mu \mathrm{g} / \mathrm{mL}$ Fungizone (Life Technologies), 48.4/ $675 \mu \mathrm{g} / \mathrm{mL}$ penicillin/streptomycin (Sigma-Aldrich), $2 \mathrm{mM}$ L-glutamine (Sigma-Aldrich), 10\% fetal bovine serum (FBS; Life Technologies), $30 \mathrm{ng} / \mathrm{mL}$ insulin-growth factor II (IGF II; ProSpec-Tany TechnoGene Ltd.), $20 \mathrm{ng} / \mathrm{mL}$ epidermal growth factor (EGF; In Vitro Technologies), and $10 \mu \mathrm{g} / \mathrm{mL}$ humulin $\mathrm{R}$ (Lilly). The pellet was disaggregated by gentle pipetting and washed with the medium by centrifugation. Finally, $1.5 \times 10^{5}$ cells were dispensed into $3 \mathrm{~mL}$ of growth medium in $60-\mathrm{mm}$ culture dishes previously coated with collagen type I (Sigma-Aldrich). The cultures were maintained at $37^{\circ} \mathrm{C}, 5 \% \mathrm{CO}_{2}$ in a humidified incubator, and cells were allowed to attach overnight. Unattached cells and cell debris were removed when the medium was replaced the following day.

\section{Establishment and culture of $L P C$ lines from primary cultures}

LPC lines were established using the protocol of StrickMarchand and Weiss. ${ }^{25}$ Primary cultures were maintained in the growth medium. During extended culture (8-12 weeks), most cells senesced and occasional epithelioid colonies emerge. These were selected and subcultured using cloning rings. By this approach, the BMEL-TAT and BMEL A-EGFP LPC lines were derived from TAT-GRE-lacZ and actin-EGFP transgenic mice, respectively. Once established, these LPC lines were passaged routinely when they attain 70-80\% confluency in a growth medium containing 5\% FBS and they did not require collagen-coated culture dishes to attach and grow.

\section{LPC differentiation protocol}

Aliquots of $3 \times 10^{5}$ LPCs were transferred to $35-\mathrm{mm}$ dishes, made up to $2 \mathrm{~mL}$ with growth medium, and maintained for 10 days to reach $100 \%$ confluency, with medium replacement every 2 days. The growth medium was then substituted with a differentiation medium (Williams' E containing $2.5 \mu \mathrm{g} / \mathrm{mL}$ Fungizone, $48.4 / 675 \mu \mathrm{g} / \mathrm{mL}$ penicillin/streptomycin, $2 \mathrm{mM}$ L-glutamine, $10 \%$ fetal bovine serum, $6.25 \mu \mathrm{g} / \mathrm{mL}$ ITS [insulin, transferrin, selenious acid; BD Bioscience], $20 \mathrm{ng} / \mathrm{mL}$ EGF, $10 \mathrm{mM}$ nicotinamide [Sigma-Aldrich], and $10^{-7} \mathrm{M}$ Dexamethasone [Sigma-Aldrich]) for a further 10 days.

\section{Treatment of LPCs with $\mathrm{NaB}$ and 5-aza C}

Cells were treated with $5 \mathrm{mM} \mathrm{NaB}$ (Sigma-Aldrich) or $4 \mu \mathrm{M} 5$-aza C (Sigma-Aldrich) by addition of a $500 \mathrm{mM}$ or $400 \mu \mathrm{M}$ respective stock solution to the culture medium. The stock solutions were prepared in a $0.1 \%$ dimethyl sulfoxide (DMSO) vehicle (Sigma-Aldrich). Cultures were treated daily for 3 days.

\section{Immunofluorescence staining of LPCs}

Anti-EpCAM (ab71916; abcam), anti-E-cadherin (3195; Cell Signaling Technology), anti-vimentin (MAB2105; R\&D Systems), and anti-HNF4 $\alpha$ (Hepatocyte nuclear factor

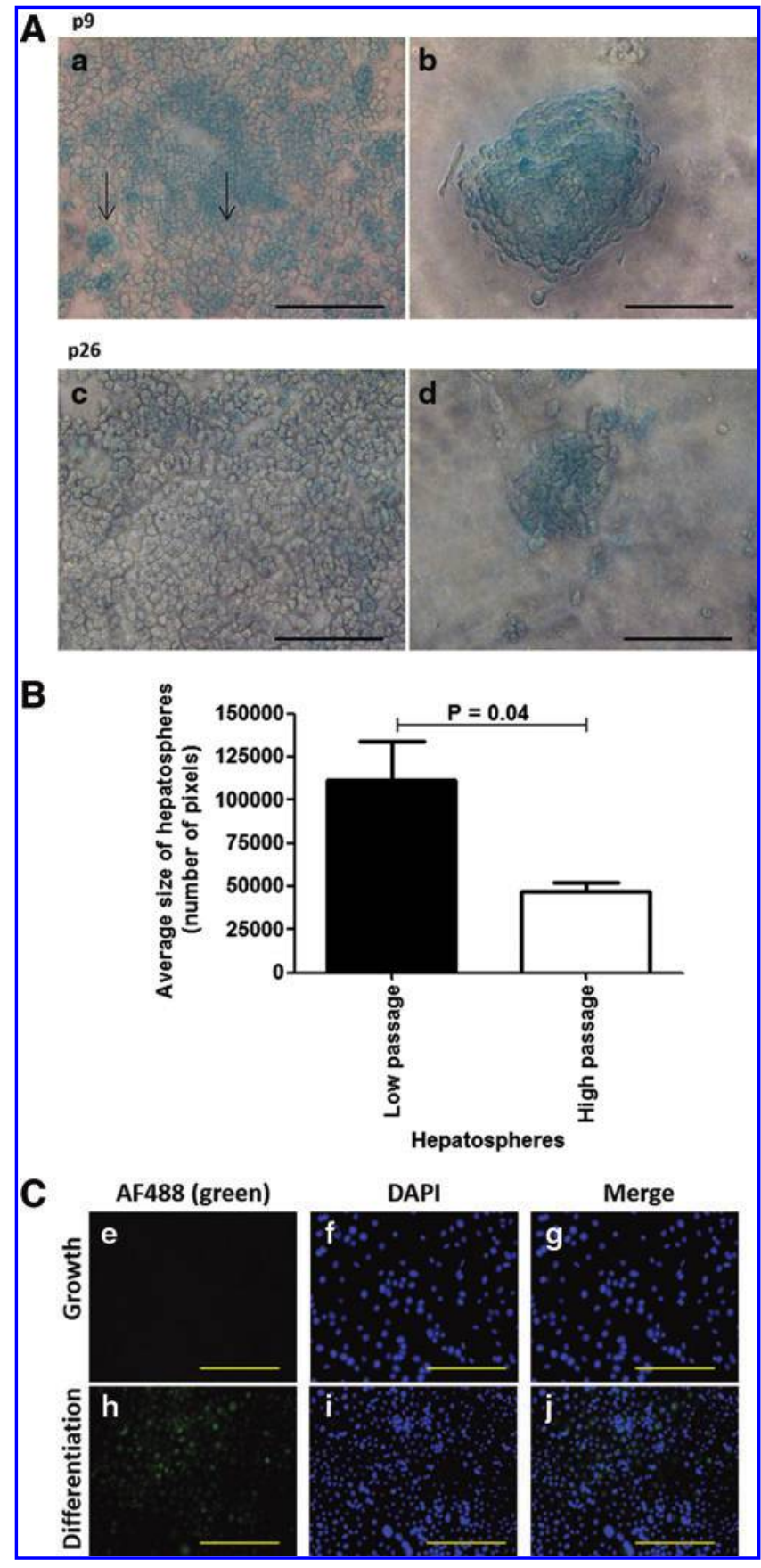

FIG. 2. (A) Increased X-gal staining accompanies differentiation of BMEL-TAT LPCs, but this diminishes with extended culture. Many $\beta$-galactosidase-positive cells were detected (arrows) following differentiation of early-passage (p9) BMEL-TAT LPCs as a monolayer (a) or spheroid clusters known as hepatospheres (b). The number of positive cells and intensity of staining were reduced in late-passage (p26) BMEL-TAT LPCs, which differentiated as a monolayer (c) or in hepatospheres (d). (B) The average size of hepatospheres also decreased in high-passage BMEL-TAT LPCs. (C) BMEL-TAT LPCs cultured in growth medium (e-g) do not express the mature hepatocyte marker HNF4a, however, differentiated LPCs $(\mathrm{h}-\mathrm{j})$ stain positively for this marker. Exposure times were $1 / 15$ and $1 / 3.5 \mathrm{~s}$ for DAPI and AF488 images, respectively. Scale bars represent $100 \mu \mathrm{m}$. Color images available online at www.liebertpub $. \mathrm{com} / \mathrm{tec}$ 
4 alpha, sc-6556; Santa Cruz) antibodies were used to stain cells grown to at least $70 \%$ confluence on collagen-coated glass coverslips. Cells were fixed in cold $\left(-20^{\circ} \mathrm{C}\right)$ acetonemethanol (1:1) for $2 \mathrm{~min}$. After three washes with phosphate-buffered saline (PBS), coverslips were blocked with $1 \%$ bovine serum albumin (BSA; Sigma-Aldrich) in PBS for $30 \mathrm{~min}$ and then incubated with the corresponding primary antibodies (at a 1/200 dilution in 1\% BSA in PBS) overnight $(16 \mathrm{~h})$ at $4^{\circ} \mathrm{C}$. Coverslips were then washed thrice with PBS followed by incubation with the appropriate secondary anti-

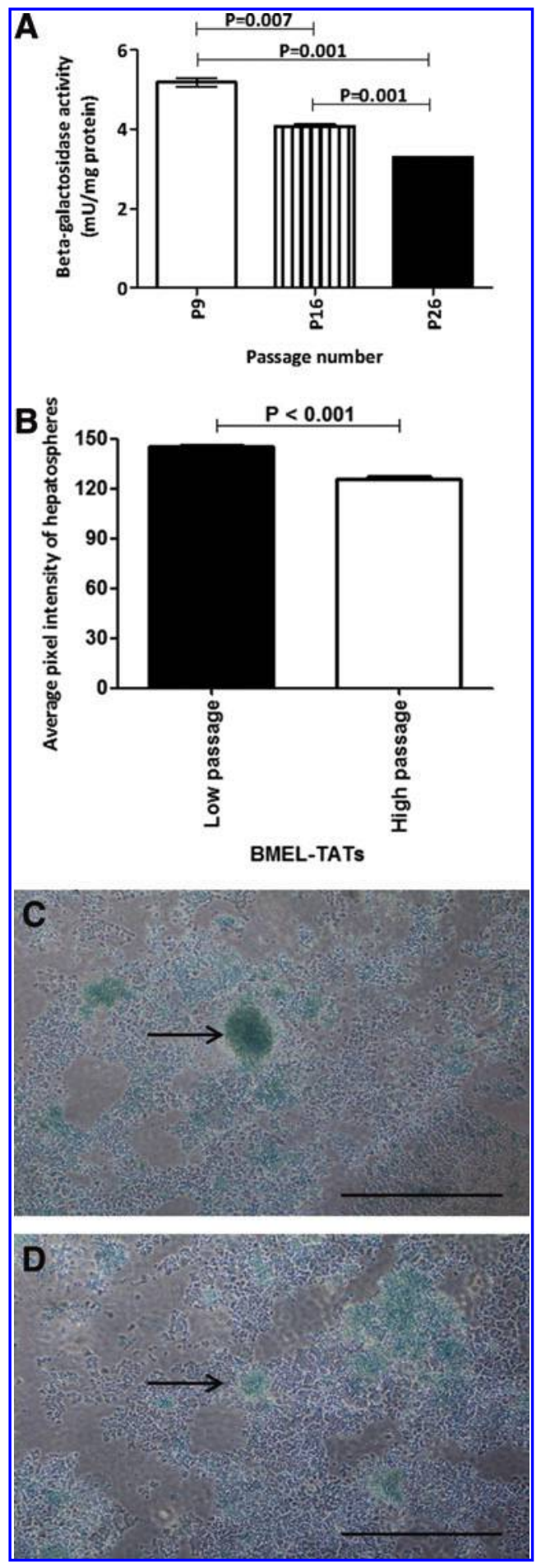

bodies (diluted $1 / 200$ in $1 \%$ BSA in PBS) for $1 \mathrm{~h}$ at room temperature. Anti-E-cadherin, anti-EpCAM, and anti-HNF4 $\alpha$ primary antibodies were labeled with the Alexa Fluor 488 goat anti-rabbit $\operatorname{IgG}(\mathrm{H}+\mathrm{L})$ secondary antibody (Invitrogen) and anti-Vimentin with the Alexa Fluor 594 goat anti-mouse IgG $(\mathrm{H}+\mathrm{L})$ secondary antibody (Invitrogen). Nuclei were stained with $25 \mathrm{ng} / \mathrm{mL}$ 2-(4-amidinophenyl)-1H -indole-6carboxamidine (DAPI; Sigma-Aldrich) in PBS for $5 \mathrm{~min}$ at room temperature. After three washes with PBS, coverslips were mounted with the Gelvatol mounting medium $(0.2 \mathrm{M}$ Tris [pH 8.5], $30 \%$ glycerol, $1 \%$ sodium azide, $105 \mathrm{mg} / \mathrm{mL}$ poly vinyl alcohol) and viewed with an Olympus IX2-ILL100 Inverted Microscope (Olympus Corporation).

\section{X-gal staining}

To assess differentiation based on the $\beta$-galactosidase reporter, X-gal (5-bromo-4-chloro-3-indolyl-D-galactopyranoside) staining was performed to determine the percentage of LPCs that differentiated into hepatocytes. Cells were grown to $100 \%$ confluence, washed in prewarmed $\left(37^{\circ} \mathrm{C}\right) \mathrm{BSS}$, and fixed in $0.25 \%$ glutaraldehyde, $0.1 \mathrm{M}$ phosphate buffer $(\mathrm{pH} 7.3)$, $5 \mathrm{mM}$ ethylenebis (oxyethylenenitrilo) tetraacetic acid (EGTA), and $2 \mathrm{mM} \mathrm{MgCl} 2$ for $3 \mathrm{~min}$ at room temperature. Cells were subsequently washed with a solution of $0.1 \mathrm{M}$ phosphate buffer ( $\mathrm{pH} 7.3$ ), $0.01 \%$ sodium dodecyl sulfate (SDS), $0.02 \%$ Nonidet-P40 (Sigma-Aldrich), and $2 \mathrm{mM} \mathrm{MgCl}_{2}$ for $3 \mathrm{~min}$ at room temperature, followed by three washes in PBS. To visualize $\beta$-galactosidase, cells were incubated overnight in X-gal staining solution $(0.1 \mathrm{M}$ phosphate buffer $[\mathrm{pH}$ 7.3], $20 \mathrm{mM}$ Tris buffer [pH 7.3], $0.01 \%$ SDS, $0.02 \%$ Nonidet$\mathrm{P} 40,2 \mathrm{mM} \mathrm{MgCl}_{2}, 5 \mathrm{mM} \mathrm{K}_{3}\left[\mathrm{Fe}\left(\mathrm{CN}_{6}\right)\right]$, and $1 \mathrm{mg} / \mathrm{mL} \mathrm{X}$-gal $)$ at $37^{\circ} \mathrm{C}$. The staining was visualized and recorded using a Nikon Eclipse TS100 inverted microscope (Nikon Corporation).

\section{Fluorescent $\beta$-galactosidase assay}

Cells were collected by centrifugation (1000 $\mathrm{g}$ for $5 \mathrm{~min}$ ), washed with BSS, and resuspended in a cell suspension

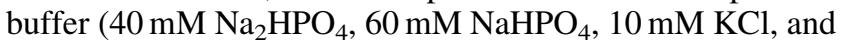
$1 \mathrm{mM} \mathrm{MgSO}_{4}$ ). Extracts were collected by centrifugation at $15,000 \mathrm{~g}$ for $10 \mathrm{~min}$ at $4^{\circ} \mathrm{C}$ and aliquots were taken for enzymatic and protein measurements. Protein concentration was determined using the Bio-Rad Bradford Protein Assay

FIG. 3. $\beta$-galactosidase activity in differentiated BMELTAT LPCs declined with extended culture. (A) $\beta$-galactosidase activity was determined by a fluorescent assay in BMEL-TAT cells at passage 9, 16, and 26, respectively. Results are shown as the mean \pm SE of $\beta$-galactosidase activity relative to $\mathrm{mg}$ of protein $(n=3)$. Statistical significance was determined using Student's $t$-test. (B) Shown are the relative X-gal staining intensities of BMEL-TAT cells in hepatospheres at low (p9) and high passage (p57). Fluorescence was quantified from 10 random cells within hepatospheres with the ImageScope Positive Pixel Counter software $(n=10)$. Significance between low- and high-passage cells was determined using Student's $t$-test. (C) Lowmagnification $(4 \times)$ phase-contrast image of low-passage (p9) BMEL-TAT hepatosphere (arrows). (D) Low-magnification (4×) phase-contrast image of high-passage (p26) BMEL-TAT hepatosphere (arrowed). Scale bars represent $100 \mu \mathrm{m}$. Color images available online at www.liebertpub.com/tec 
kit (Bio-Rad) by mixing $2 \mu \mathrm{L}$ of extract with $798 \mu \mathrm{L}$ of diluted reaction mix and $200 \mu \mathrm{L}$ of reagent in plastic cuvettes. Absorbance was measured in the Eppendorf BioPhotometer at $600 \mathrm{~nm}$ along with BSA protein standards.

$\beta$-galactosidase assays were conducted in microtiter plates and used $200 \mu \mathrm{L}$ reaction volumes, each containing $2 \mu \mathrm{L}$ of cellular extract and $198 \mu \mathrm{L}$ of 4-methylumbelliferyl$\beta$-D-glucuronide (MUG) substrate solution (51 mg of MUG dissolved in $10 \mathrm{~mL}$ of cell suspension buffer and $90 \mathrm{~mL}$ of sterile water). Measurements were taken every $2 \mathrm{~min}$ for a total of $2 \mathrm{~h}$, and the $\beta$-galactosidase activity was determined by averaging the rate of 4-methylumbelliferone (MU) production. All experiments were repeated at least thrice. Fluorescence was determined using the FLUOstar OPTIMA plate reader (BMG Labtech $\mathrm{GmbH}$; filter set: $370 \mathrm{~nm}$ excitation and $460 \mathrm{~nm}$ emission).

\section{ImageScope quantification}

To determine the average X-gal staining and EGFP intensity, fluorescent images were collected from 10 random cells within hepatospheres or 10 fields of view, respectively, for each cell line or treatment group using the Olympus IX2ILL100 Inverted Microscope (Olympus Corporation) and analyzed using the Positive Pixel Count Algorithm with the Aperio ImageScope software (Aperio Technologies). For EGFP intensity, this process was repeated every $24 \mathrm{~h}$ for 3 days to assess the effect of each treatment with time.

\section{Flow cytometry}

Cells were washed with BSS, treated with trypsinethylenediaminetetraacetic acid (EDTA; Invitrogen), and then resuspended in PBS. Samples were analyzed using the FACSCalibur Flow Cytometer (Becton Dickinson) and CellQuest Pro software (Becton Dickinson). Dead cells were excluded from analysis by forward- and side-scatter gating. A minimum of 9000 events were collected for each sample.

\section{Results}

\section{LPCs express epithelial and not mesenchymal markers}

The epithelial phenotype of the LPCs was confirmed by expression of E-cadherin and EpCAM surface markers. BMEL-TAT and BMEL A-EGFP LPCs express E-cadherin (Fig. 1, a and j) as well as EpCAM (Fig. 1, d and m). BMEL-TAT is negative for the mesenchymal cell surface marker vimentin (Fig. 1, g and i) and the majority ( $>95 \%)$ of BMEL A-EGFP cells were vimentin negative (Fig. 1p), with rare cells showing positivity (data not shown).

\section{Differentiated BMEL-TAT LPCs express HNF4 $\alpha$ and the $\beta$-galactosidase reporter, but lose the ability to express this reporter after extended passaging}

To demonstrate the utility of the TAT-driven $\beta$-galactosidase reporter, passage (p)9 BMEL-TAT LPCs were differentiated and stained with X-gal. Differentiated cells were larger (Fig. 2a, arrowed), with the larger cells having substantially more $\beta$ galactosidase activity as indicated by the blue staining (Fig. 2a). Differentiated cells formed spheroid clusters that we designate as hepatospheres; all cells within the hepatospheres stained

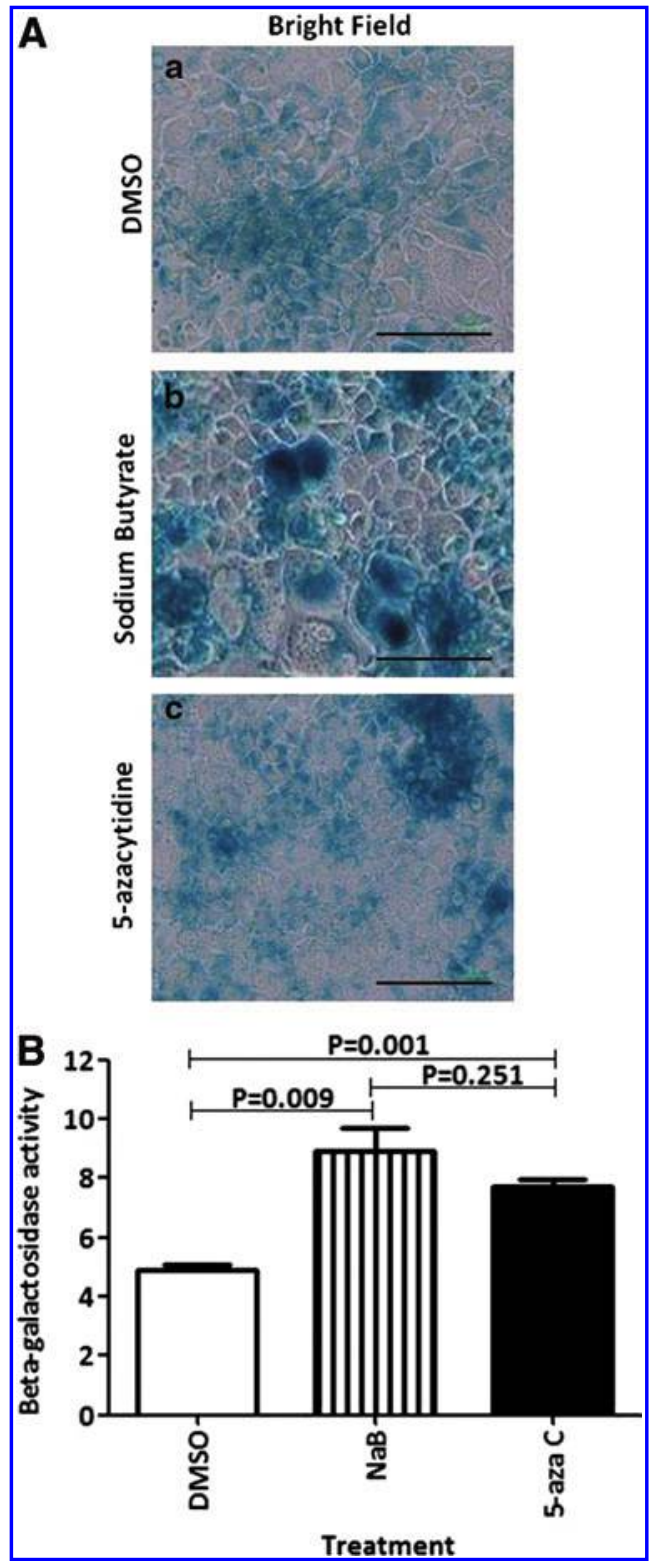

FIG. 4. $\mathrm{NaB}$ and 5-aza $\mathrm{C}$ enhanced $\beta$-galactosidase staining and activity in differentiated BMEL-TAT LPCs. (A) BMEL-TAT LPCs were treated with $0.1 \%$ dimethyl sulfoxide (DMSO) vehicle (a), $4 \mathrm{mM} \mathrm{NaB}$ (b), or $5 \mu \mathrm{M} 5$ aza $\mathrm{C}$ (c) for 3 days, then differentiated and stained with $\mathrm{X}$ gal and visualized under brightfield illumination. Scale bars represent $100 \mu \mathrm{m}$. (B) Cells were treated with $4 \mathrm{mM} \mathrm{NaB}$, $5 \mu \mathrm{M} 5$-aza C, or vehicle control $(0.1 \%$ DMSO) for 3 days and then differentiated. The results are shown as the mean $\pm S E$ of $\beta$-galactosidase activity per $\mathrm{mg}$ of protein for three independent experiments. Statistical significance was determined using Student's $t$-test. Color images available online at www.liebertpub.com/tec

positively with the majority of cells staining intensely (Fig. 2b). Undifferentiated BMEL-TAT LPCs did not stain (results not shown) and are similar to the negative cells that surround the hepatosphere (Fig. 2b). Differentiated p26 cells show significantly fewer positive cells both in monolayers (Fig. 2c) and in hepatospheres (Fig. 2d). Furthermore, the average size of hepatospheres in low-passage LPCs was 2.4-fold higher than high- 
passage hepatospheres (Fig. 2B). The differentiated status of the BMEL-TAT LPCs was confirmed by expression of the mature hepatocyte marker, HNF4 $\alpha$. BMEL-TAT cells maintained in the growth medium did not express $\mathrm{HNF} 4 \alpha$ (Fig. 2, e-g), while differentiated LPCs expressed nuclear HNF $\alpha$ (Fig. 2, h-j).

The $\beta$-galactosidase activity was measured to quantify reporter expression in differentiated BMEL-TAT LPCs at p9, p16, and p26. A decrease of reporter expression with increasing passage number (Fig. 3A) was evident. The level of $\beta$-galactosidase reporter expression was $5.19,4.08$, and $3.30 \mathrm{mU} / \mathrm{mg}$ protein for BMEL-TAL LPCs p9, p16, and p26 cells, respectively.

The level of $\beta$-galactosidase activity in undifferentiated BMEL-TAT LPCs was very low $(0.51 \mathrm{mU} / \mathrm{mg}$ protein, data not shown). This is similar to the activity of BMEL A-EGFP LPCs $(0.24 \mathrm{mU} / \mathrm{mg}$ protein), which do not have this reporter construct. Following differentiation, the activity was $4.73 \mathrm{mU} / \mathrm{mg}$ protein representing a substantial increase of nearly 10 -fold relative to the negative control.

To determine whether the relative X-gal staining intensity of hepatosphere cells changed with increasing passage, BMELTAT LPCs were analyzed by ImageScope analysis software. High-passage (p26) cells within hepatospheres showed a decrease in average pixel intensity of $15.4 \%$ compared to lowpassage (p9) cells within hepatospheres $(126 \pm 0.9$ to 145.4 \pm 0.9; Fig. 3B). Furthermore, phase-contrast microscopy shows low-passage BMEL-TAT hepatospheres (Fig. 3C) to be visibly smaller than the high-passage equivalents (Fig. 3D).

\section{Treatment with $\mathrm{NaB}$ and 5-aza $C$ increases \\ $\beta$-galactosidase activity in differentiated BMEL-TAT LPCS}

$\mathrm{X}$-gal staining was more intense in differentiated LPCs that were treated with either $\mathrm{NaB}$ (Fig. 4b) or 5-aza C (Fig. 4c) compared with the DMSO-treated controls (Fig. 4a). Notably, a subset of NaB-treated LPCs displayed higher levels of X-gal staining than the majority of the culture (Fig. 4b). In contrast, 5-aza C-treated LPCs have fewer intensely staining cells, but instead showed many more cells with a high level of staining throughout the culture (Fig. 4c). The total number of positive cells was not significantly different in the respective cultures (data not shown); $\mathrm{NaB}$ and 5-aza $\mathrm{C}$ increased $\beta$-galactosidase activity 1.8 - and 1.6-fold, respectively, relative to the DMSO control.

\section{BMEL A-EGFP cells undergo an epithelial to mesenchymal transition during extended culture}

BMEL A-EGFP LPCs lose their epithelial phenotype after extended culture. The epithelial markers E-Cadherin and EpCAM were no longer expressed in BMEL A-EGFP after extended passaging (p57, Fig. 5, a and d), but present at p10 (Fig. 1, j and m). The opposite was true for the mesenchymal cell surface marker, vimentin. This was strongly expressed in high-passage (p57) BMEL A-EGFP (Fig. 5g), but not seen in low-passage (p10) BMEL A-EGFP (Fig. 1p).

\section{Treatment with $\mathrm{NaB}$ and 5-aza $C$ increases EGFP activity of low-passage (p10) and high-passage (p57) BMEL A-EGFP LPCs}

To ascertain whether a constitutive reporter in LPCs responds in a similar manner to a reporter that is differentiation dependent, the fluorescence of BMEL A-EGFP (p10 and p57) cells treated with $\mathrm{NaB}$ or 5-aza $\mathrm{C}$ was analyzed each day for 3 days. This showed an increase in average pixel intensity for p10 BMEL A-EGFP cells from day 0 to 3 when treated with $\mathrm{NaB}$ (from 1.5 to 5.6) and with 5-aza $\mathrm{C}$ (from 1.2 to 6.5) (Fig. 6A). Extensively passaged cells (p57) showed an average pixel intensity increase from 0.1 to 1.1 ,
FIG. 5. Highly passaged BMEL AEGFP LPCs lose epithelial and gain mesenchymal cell markers. High-passage (p57) BMEL A-EGFP LPCs do not stain for epithelial markers ECadherin $(\mathbf{a}-\mathbf{c})$ or for EpCAM (d-f). The majority $(>95 \%)$ of cells are positive for the mesenchymal marker vimentin (g-i). Exposure times were $1 / 20$ and $1 / 4$ s for DAPI and AF488/ 594 images, respectively. Scale bars represent $100 \mu \mathrm{m}$. Color images available online at www.liebertpub .com/tec

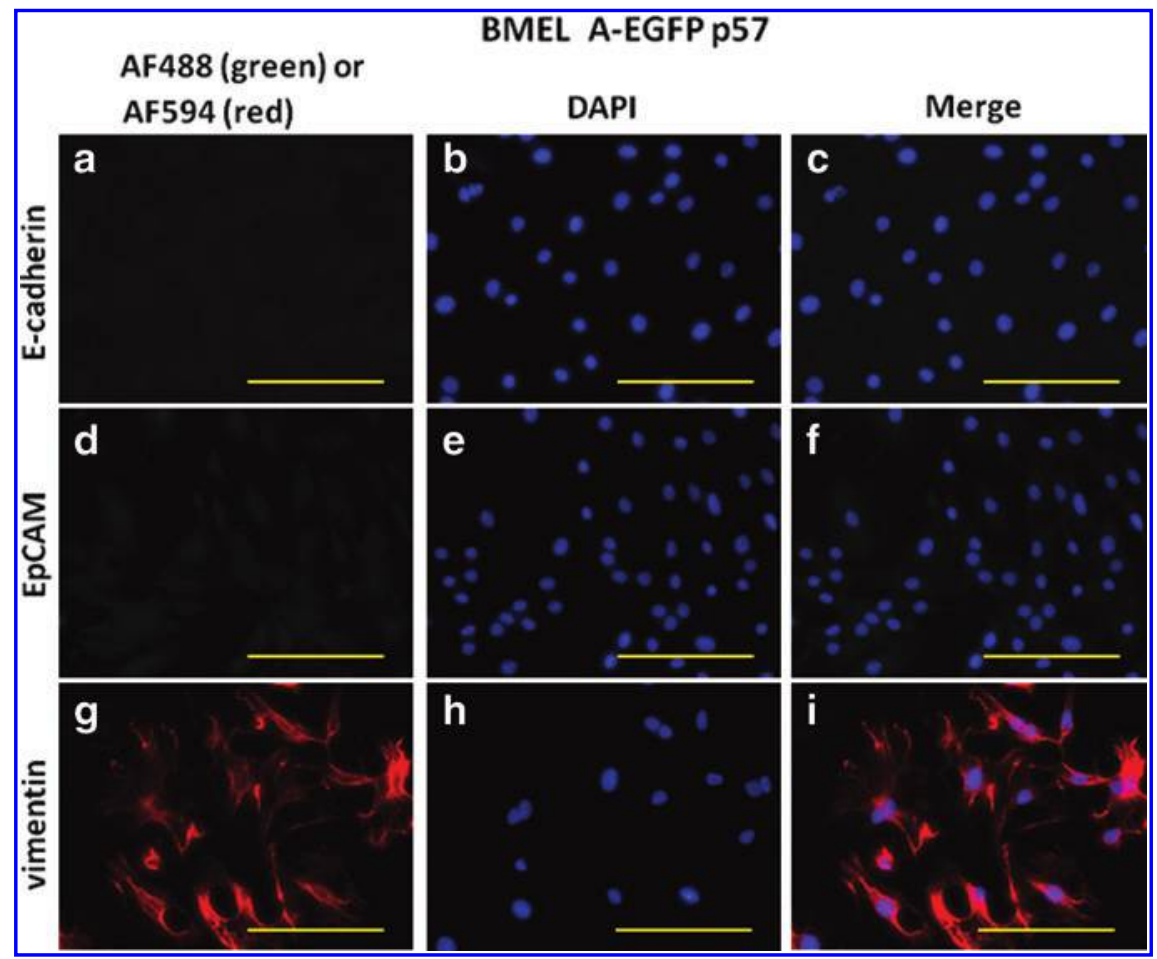




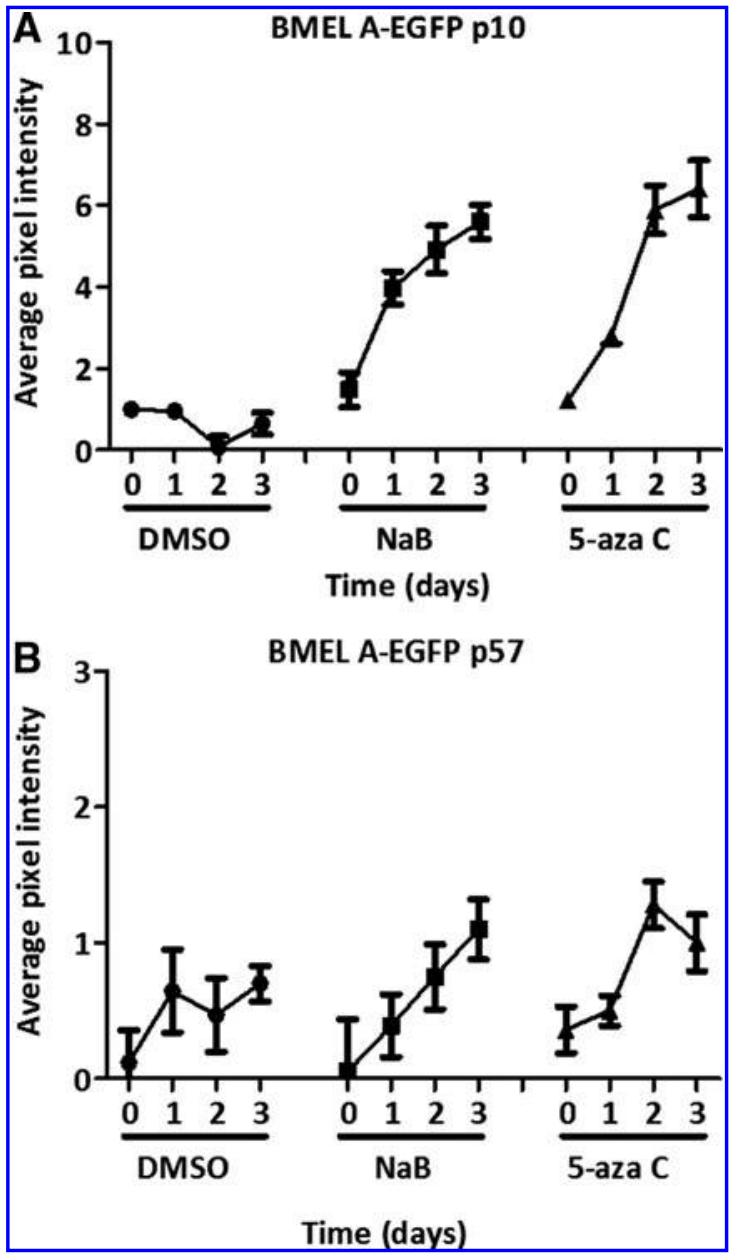

FIG. 6. EGFP fluorescence in BMEL A-EGFP LPCs increases following treatment with $\mathrm{NaB}$ and 5-aza $\mathrm{C}$. Shown are the relative EGFP fluorescent intensities of BMEL AEGFP at p10 (A) and at p57 (B) over 3 days of treatment with DMSO, NaB, or 5-aza C. Fluorescence was quantified from cultured cells in 10 random fields of view with the ImageScope Positive Pixel Counter software $(n=10)$. Significance between day 0 and 3 fluorescence was determined using Student's $t$-test. The $p$-value for $\mathrm{p} 10$ cells treated with $\mathrm{NaB}$ and 5 -aza $\mathrm{C}$ was $<0.0001$ and for DMSO it was not significant. Changes in fluorescence were significant for $\mathrm{p} 57$ cells treated with $\mathrm{NaB}, 5$-aza $\mathrm{C}$, and DMSO control (all $p<0.05$ ) with $p$-values of $0.0309,0.0292$, and 0.0187 , respectively.

0.4 to 1 , and 0 to 0.7 after treatment with $\mathrm{NaB}, 5$-aza $\mathrm{C}$, and DMSO, respectively (Fig. 6B).

Flow cytometry-confirmed treatment with $\mathrm{NaB}$ or 5 -aza $\mathrm{C}$ enhanced the activity of the EGFP reporter in the BMEL A-EGFP LPCs. Treatment with $\mathrm{NaB}$ or 5-aza $\mathrm{C}$ increased fluorescence by 4.7- and 4.4-fold, respectively, relative to LPCs treated with DMSO. There was no shift in EGFP expression in DMSO-treated LPCs relative to the medium alone (Fig. 7).

\section{Discussion}

The current study demonstrates that epigenetic mechanisms downregulate the expression of transgenes in two independent LPC lines during culture. This diminishes the utility of the cell lines for tracking or lineage evaluation

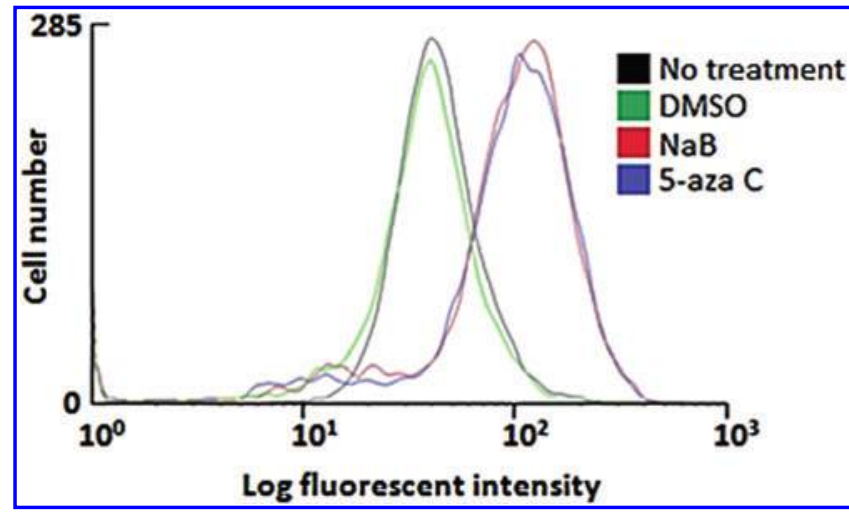

FIG. 7. $\mathrm{NaB}$ or 5-aza $\mathrm{C}$ increases in EGFP expression in BMEL A-EGFP LPCs. EGFP levels were analyzed by flow cytometry following no treatment (black) or after 3 days of treatment with DMSO (control) (green), NaB (red), or 5-aza C (blue), respectively. For each sample, over 9000 events were acquired in the list mode and analyzed with the CellQuest Pro software (Becton Dickinson). Color images available online at www.liebertpub.com/tec

experiments or, in extreme cases, renders them unusable. We have shown that two chemical epigenetic modulators, $\mathrm{NaB}$ and 5-aza $\mathrm{C}$, enhance transgene expression in these mouse LPC lines. Our findings highlight a number of important principles associated with maintaining transgene expression in stem and progenitor cells.

In BMEL-TAT LPCs, a decrease in $\beta$-galactosidase activity accompanies increased passage number. There are two possible explanations; either epigenetic changes have suppressed the ability of the cells to differentiate or they have downregulated expression of the reporter. We suggest the latter is more likely for two reasons. First, the $\mathrm{NaB}$ and 5-aza $\mathrm{C}$ treatments increased expression of both the constitutive (EGFP) and the differentiation ( $\beta$-galactosidase) reporter. Second, the level of reporter expression was increased on a per cell basis and not numbers of positive cells. These findings suggest that the epigenetic changes affect the level of transgene expression and not the ability of the cell to express the transgene.

The extensively cultured BMEL A-EGFP (p57) LPCs increased reporter fluorescent levels following treatment with $\mathrm{NaB}$ or 5-aza $\mathrm{C}$, although the increase was not as large as that seen with BMEL-TAT LPCs or the lower passage BMEL A-EGFP (p10) LPCs. This suggests that they may be more resistant to epigenetic modulators to reverse silencing of the reporter gene. The BMEL A-EGFP LPCs undergo an epithelial to mesenchymal-like transition after extensive passaging that may render them more resistant to epigenetic modulation. This highlights the need to avoid epigenetic changes in cell lines carrying reporter genes of interest or risk losing their utility.

\section{Conclusion}

This study shows that epigenetic mechanisms diminish reporter gene expression in LPCs and, importantly, this can be reversed. This is especially significant for the BMELTAT LPCs as this transgenic mouse is no longer available to derive new cell lines. Treatment with $\mathrm{NaB}$ or 5 -aza $\mathrm{C}$ enhances transgene expression in a subpopulation that allows for their 
selection and use in future experiments. These findings suggest that epigenetic mechanisms may operate during the maintenance of stem and progenitor cell lines and highlight the need to adopt culture conditions that minimize or eliminate these deleterious effects. If this is not possible, then treatment with epigenetic modifiers as we have shown here may restore sufficient reporter activity and utility of the cell line.

\section{Acknowledgments}

This research has received grant support from the National Health and Medical Research Council of Australia and the Cancer Council Western Australia. Additional funding was provided by the Ride to Conquer Cancer from the Harry Perkins Institute of Medical Research. We thank Heidi Peters of the University of Melbourne for supplying the BMEL A-EGFP cell line.

\section{Disclosure Statement}

No competing financial interests exist.

\section{References}

1. Hochedlinger, K., and Jaenisch, R. Nuclear transplantation: lessons from frogs and mice. Curr Opin Chem Biol 14, 741, 2002.

2. Kim, Y., Lee, D., Kang, J., Lee, Y., Chung, J., Roh, J., Kim, S., and Lee, M. Reversing the silencing of reporter sodium/ iodide symporter transgene for stem cell tracking. J Nucl Med 46, 305, 2005.

3. Huangfu, D., Maehr, R., Guo, W., Eijkelenboom, A., Snitow, M., Chen, A.E., and Melton, D.A. Induction of pluripotent stem cells by defined factors is greatly improved by small-molecule compounds. Nat biotechnol 26, 795, 2008.

4. Bolden, J., Peart, M., and Johnstone, R. Anticancer activities of histone deacetylase inhibitors. Nat Rev Drug Discov 5, 769, 2006.

5. Yoo, C., and Jones, P. Epigenetic therapy of cancer: past, present and future. Nat Rev Drug Discov 5, 37, 2006.

6. Daigle, D., Gradoville, L., Tuck, D., Schulz, V., Wang'ondu, R., Ye, J., Gorres, K., and Miller, G. Valproic acid antagonizes the capacity of other histone deacetylase inhibitors to activate the Epstein-Barr virus lytic cycle. J Virol 85, 5628, 2011.

7. Barnard, J., and Warwick, G. Butyrate rapidly induces growth inhibition and differentiation in HT-29 cells. Cell Growth Differ 4, 495, 1993.

8. Mu, D., Gao, Z., Guo, H., Zhou, G., and Sun, B. Sodium butyrate induces growth inhibition and apoptosis in human prostate cancer DU145 cells by up-regulation of the expression of annexin A1. PLoS One 8, 74922, 2013.

9. Dokmanovic, M., Clarke, C., and Marks, P. Histone deacetylase inhibitors: overview and perspectives. Mol Cancer Res 5, 981, 2007.

10. Rada-Iglesias, A., Enroth, S., Ameur, A., Koch, C.M., Clelland, G.K., Respuela-Alonso, P., Wilcox, S., Dovey, O.M., Ellis, P.D., and Langford, C.F. Butyrate mediates decrease of histone acetylation centered on transcription start sites and down-regulation of associated genes. Genome Res 17, 708, 2007.
11. González, F., Boué, S., and Belmonte, J. Methods for making induced pluripotent stem cells: reprogramming a la carte. Nat Rev Gen 12, 231, 2011.

12. Lin, J., Haffner, M.C., Zhang, Y., Lee, B.H., Brennen, W.N., Britton, J., Kachhap, S.K., Shim, J.S., Liu, J.O., and Nelson, W.G. Disulfiram is a DNA demethylating agent and inhibits prostate cancer cell growth. Prostate 71, 333, 2011.

13. Cedar, H., and Bergman, Y. Programming of DNA methylation patterns. Annu Rev Biochem 81, 97, 2012.

14. Jones, P., and Taylor, S. Cellular differentiation, cytidine analogs and DNA methylation. Cell 20, 85, 1980.

15. Dahl, C., Grønbæk, K., and Guldberg, P. Advances in DNA methylation: 5-hydroxymethylcytosine revisited. Clin Chim Acta 412, 831, 2011.

16. Okabe, M., Tsukahara, Y., Tanaka, M., Suzuki, K., Saito, S., Kamiya, Y., Tsujimura, T., Nakamura, K., and Miyajima, A. Potential hepatic stem cells reside in EpCAM+ cells of normal and injured mouse liver. Development 136, 1951, 2009.

17. Conigliaro, A., Brenner, D., and Kisseleva, T. Hepatic progenitors for liver disease: current position. Stem Cells Cloning 3, 39, 2010.

18. Lowes, K.N., Brennan, B.A., Yeoh, G.C., and Olynyk, J.K. Oval cell numbers in human chronic liver diseases are directly related to disease severity. Am J Pathol 154, 537, 1999.

19. Dollé, L., Best, J., Mei, J., Al Battah, F., Reynaert, H., van Grunsven, L.A., and Geerts, A. The quest for liver progenitor cells: a practical point of view. J Hepatol 52, 117, 2010.

20. Burra, P., Bizzaro, D., Ciccocioppo, R., Marra, F., Piscaglia, A.C., Porretti, L., Gasbarrini, A., and Russo, F.P. Therapeutic application of stem cells in gastroenterology: an up-date. World J Gastroenterol 17, 3870, 2011.

21. Lombard, C., Prigent, J., and Sokal, E. Human liver progenitor cells for liver repair. Cell Med 5, 1, 2013.

22. Montoliu, L., Blendy, J.A., Cole, T.J., and Schütz, G. Analysis of perinatal gene expression: hormone response elements mediate activation of a lacZ reporter gene in liver of transgenic mice. PNAS 92, 4244, 1995.

23. Tirnitz-Parker, J.E., Tonkin, J.N., Knight, B., Olynyk, J.K., and Yeoh, G.C. Isolation, culture and immortalisation of hepatic oval cells from adult mice fed a choline-deficient, ethionine-supplemented diet. Int J Biochem Cell Biol 39, 2226, 2007.

24. Hadjantonakis, A.K., Gertsenstein, M., Ikawa, M., Okabe, M., and Nagy A. Generating green fluorescent mice by germline transmission of green fluorescent ES cells. Mech Dev 76, 79, 1998.

25. Strick-Marchand, H., and Weiss, M.C. Inducible differentiation and morphogenesis of bipotential liver cell lines from wild-type mouse embryos. Hepatology. 36, 794, 2002.

Address correspondence to: George Cheng Yeoh, PhD The Centre for Medical Research Harry Perkins Institute of Medical Research 6 Verdun Street Nedlands, WA 6009 Australia

E-mail: george.yeoh@uwa.edu.au

Received: March 26, 2015 Accepted: May 15, 2015 Online Publication Date: July 3, 2015 